Pig Housing and the Environment

Occasional Publication No. 11-British Society of Animal Production 1987

edited by A. T. Smith and T. L. J. Lawrence

\title{
ENVIRONMENTAL COMPONENTS OF PIG HEALTH
}

\author{
J. SVENDSEN and L. S. SVENDSEN
}

Swedish University of Agricultural Sciences, Department of Farm Buildings, Lund, Sweden

\begin{abstract}
O ne of the limiting factors in pig production is the ill health of the animals. Besides the effect of overt disease, subclinical disease and more subtle disturbances in health may be a continual problem affecting all production parameters. These disturbances range from reproductive problems such as infertility, neonatal health problems, gastrointestinal and respiratory problems during the growing-finishing period, and injuries at all production stages.

The causes of many of these disturbances and losses are multifactorial, resulting from an interaction between different environmental factors (stressors) and the animals. Many health problems are not initially due to infections but infections may appear as a secondary factor. Where bacteria, viruses and parasites are involved, the pig's immune status and ability for immune defence is often the determinant for disease. Unfavourable environmental factors do not result in a specific disease if the agent is missing.

When animals are housed, their life form is altered. Housing creates limits in their choices, freedom of movement, activities, and feeding. While pigs generally have a talent for adapting to the environment, modern production methods have made it difficult for some animals to cope with their situation. They become stressed, and especially if this stress is prolonged, negative effects appear, generally reflected in their state of health.
\end{abstract}

\section{INTRODUCTION}

Over the past two decades, considerable structural changes within pig production have taken place in most countries. These changes have been necessary due both to consumer pressure for inexpensive meat of high quality and in order to produce income and working conditions comparable with those of other occupations. In modern animal production, few people look after many animals in a normal working day. The rationalization of building design and the introduction of new feeding systems and automated climatic control has helped to make this possible.
Animal care in modern housing not only requires a knowledge of the inherent biological problems but also requires a certain amount of technical expertise. In the same manner, the focus of veterinarians' work has changed so that preventive medicine and the solving of problems at herd level have become all important.

\section{HERD HEALTH PROBLEMS}

\section{General features}

In spite of the structural changes within pig production and the application of new techniques there has not, in general, been a decrease in mortality rates. In many countries in breeding herds pre-weaning losses of $20 \%$ or more are still being reported, about $80 \%$ of these losses occurring within 2 to 3 days after farrowing when the piglet is at its most immature state. Many of these losses are due to piglets dying during farrowing, to crushed or traumatized pigs, and to weak and/or undersized piglets not being able to withstand a hostile environment. The causes of death vary greatly and the percentage loss varies from herd to herd, but infections are rarely implicated.

Disease patterns and frequencies have also changed considerably due to changes in housing systems and in management practices such as the establishment of closed herds, an increase in herd size and changes in the structure of the pig industry leading to many contracts between farms. Diseases such as atrophic rhinitis, enzootic pneumonia and $E$. coli associated syndromes have increased in importance. Previously they were hardly considered, or even recognized.

Many of the most important of the diseases, injuries, disturbances and losses in modern pig production are multifactorial, resulting from an interaction between different environmental factors and the animal. The disturbances include reproduction problems, respiratory and gastrointestinal diseases, pressure sores, traumatizations, behavioural abnormalities, poisonings and feeding-dependent illnesses. Where infectious agents such as bacteria, viruses and parasites are, involved, the animal's immune status and its capacity for immune response are often the determinants for 
disease. Immunity again, may be affected by environmental factors or stressors.

Normally, an animal is in balance with infectious agencies and other factors in its environment. If an infected animal is stressed in some manner, for example by an increased dose rate of an infectious agent, by farrowing, by transport or by changed husbandry routines and by exposure to unhealthy climatic conditions this balance may be disturbed by, for example, an altered humoral immunity, by a changed immune clearance or by the 'barrier effect' of the bacterial flora of the digestive tract. The result may be subclinical or clinical disease. Thus, unfavourable environmental circumstances in a herd create conditions for multiplication of infectious agents which were present previously without expressing pathogenicity (Vannier, Tillon, Madec and Morisse, 1983). In the same manner, a reduction in stress due to optimal feeding, good hygiene or reduced stocking density will have a beneficial influence on animal health by increasing the threshold for the onset of disease.

\section{Effect of stress}

Selye (1956) defined stress as the reactions occurring in the body in response to different external influences or 'stressors'. At present, the effect of stress on the biological system is not fully understood. The body responds to increased physical or psychological demands by releasing adrenocorticotropin (ACTH) from the anterior pituitary, which in turn stimulates glucocorticoids and catecholamine production, involving the sympathetic nervous system. These hormones adapt the body to stressors by affecting the cardiovascular, energy-producing, and immune systems. Depending upon the type of stress, it is likely that a number of hormones may individually or in combination affect the amount and duration of ACTH secreted. As a result of this hormonal indigestion, negative side effects may appear, although they may not be immediately recognized as such.

Although a stress response in general is supposed to be beneficial to the organism, if it is prolonged, the daily variation of the hormone levels will be disturbed (Fabiansson, 1986). For more than a decade it has been known that prolonged secretion of stress hormones, particularly corticosteroids, contributes to regression of the lymphoid tissues (Selye, 1974; Freeman, 1975).

Studies of a variety of immune events in chickens, calves, pigs and mice exposed to different stressors showed that in every species, stress caused significant changes in some component of the immune system. These changes depended on several variables, such as type of stressor, duration of exposure, type of immune response, breed type and whether the animals were naive or sensitized to the challenging agent (Kelley, 1983). Disease occurs when this enhanced or depressed immune response interacts with an infective agent (Webster, 1970).
Generally, pigs adapt to new environments well, perhaps because much of their 'natural' behaviour was determined by environmental necessity rather than by an internal instinctive response. However, modern production methods, with many pigs housed in small areas with little to do other than to eat, to drink and to sleep, has made it difficult for some individuals to cope with this situation. The environment becomes a disability for the animal, it becomes stressed and if this stress is prolonged, deleterious effects will appear.

However, it is the total effect of the different environmental factors, including the presence of various types of contaminants, which determine herd health. Since the number of possible combinations is high, and the clinical manifestation of disease often remains the same, it is usually very difficult to determine causal relationships. In the case of infectious disease, a primary requirement is the presence of the infective agent in the population. Unfavourable environmental factors do not result in a specific disease if the agent is missing.

\section{PIG HEALTH AND THE ENVIRONMENT}

The housing of animals creates limits in their choices. in their freedom of movement and in their general and feeding activities. It interferes with group formation and social organization; it alters the possibility of differentiating between eating areas, lying areas and dunging areas; it removes the possibility of escape; it changes the pattern of social contacts, conflicts, and mother-offspring interactions; changes food intake and eating behaviour and it limits or makes impossible the normal expression of certain behavioural traits. Thus, when animals are housed, their life form changes and in some cases, illness or injuries may result. The causes of these health disturbances are generally multifactorial, resulting from an interaction between the genetic makeup of the individual and the 'new' environment.

The following will present examples of some of the major health problems in pig production and discuss the environmental components that have been associated with their appearance.

\section{Reproduction problems}

General. Reproduction problems are a major concern to pig producers. Although pigs are considered to have exceptionally high fertility, the results of two large surveys suggest otherwise. Excluding sexually mature animals failing to come into oestrus, BeVier and Bäckström (1980) and Hurtgen and Leman (1980) found that proportionately about 0.38 of more than 22000 matings of sows and gilts did not lead to farrowings. While the infectious and genetic origins of such failures are fairly well known, the environmental factors are not as well delineated. 
Early embryonic death, abortions and fertility. Alteration of the fertility of sows and gilts in relation to season of the year has been recognized in many countries. Farrowing rates are about 0.15 lower for summer matings than for those made in the winter. Many of these infertile matings are associated with a delayed return to oestrus, suggesting that the incidence of early embryonic death or abortion is also increased during these months (Corteel, Signoret and du Mesnil du Buisson, 1964; Love, 1978; Paterson, Barker and Lindsay, 1978; Stork, 1979; and Hurtgen and Leman, 1980).

High ambient temperatures reduce conception rate and embryonic survival (Heitman, Hughes and Kelly, 1951; Warnick, Wallace, Palmer, Sosa, Duerre and Caldwell, 1965; Tompkins, Heidenreich and Stob, 1967; Edwards, Omtvedt, Turman, Stephens and Mahoney, 1968; Omtvedt, Nelson, Edwards, Stephens and Turman, 1968; Teague, 1970; Wildt, Riegle and Dukelow, 1975). Ambient temperatures from 27 to $29^{\circ} \mathrm{C}$ cause the internal temperature of the sow to increase and the resulting high body temperature is maintained even when the external temperatures begins to decrease. Thus, the length of time a sow is heat stressed is greater than the length of time the external temperature remains above the 'dangerous' level (Venturi and Patrizia, 1986) and high ambient temperatures may be partially responsible for decreased fertility during the summer (Hurtgen, 1981)

Experimentally, heat stress is most detrimental to fertility when females are exposed to temperatures above $30^{\circ} \mathrm{C}$ during the first 30 days after mating or within 10 days of farrowing (Hurtgen, 1981). Wrathall and co-workers (Trujano and Wrathall, 1986) recently have shown that cultured porcine embryos at a very early stage are very sensitive to small increases in temperature, leading to abnormalities and growth retardation. Thus, high maternal temperatures probably do have a direct effect on the development and survival of porcine embryos.

The 'not in pig' sow. The 'not in pig' (NIP) sow - one that is served, diagnosed as being pregnant, does not exhibit an obvious return to oestrus, but fails to farrow at the expected parturition date, is another reproductive problem often present in large herds. For example, more than $20 \%$ of 52 NIP sows culled in Canada had been diagnosed as 'normal' (Almond, Bosu, King and Wilson, 1983). Managerial factors such as suboptimal record keeping, erroneous pregnancy diagnosis and inadequate heat detection may contribute to the occurrence of NIP sows.

Many herdsmen want to treat reproductive problems with chemotherapeutic agents, as for infectious diseases. However, the majority of the problems encountered in large confined pig herds are the direct result of reproductive mismanagement. An example is the 'floating sow syndrome', which is characterized by 'lost' or forgotten non-pregnant sows taking up space in gestation pens and which is usually due to the lack of permanent sow identification and inadequate oestrous detection procedures. In field situations, reproductive disorders rarely have an endocrine basis (BeVier and Dial, 1983), although stress may certainly play a rôle.

Gilt breeding. Gilts have a lower farrowing rate and show more seasonal variation than sows. If housed outdoors or in 'in/out' systems, they tend to exhibit an earlier seasonal decrease in fertility compared with sows and with gilts housed indoors (Leman, Greenley and Barrick, 1986). The farrowing rate is also reduced if their growth is poor (Dyck, 1973), indicating that food consumption in gilts must be greater than that required for maintenance in order to ensure adequate fertility. The effect of food restriction to a level that only maintains weight in gilts appears to be that of either inducing a cessation of oestrous cycling and/or reducing ovulation, or that of impairing embryo implantation.

Thin sow syndrome. An additional reproduction problem related to modern productions methods is the 'thin sow syndrome' (MacLean, 1969). The modern lean pig is more sensitive to changes in body weight than the older type of pig. When this is coupled with restricted feeding during gestation, reducing further the fat layer which would otherwise give protection from environmental adversity, the result is one of animals that are much more sensitive to or affected by environmental changes.

This syndrome is an increasing problem in modern, intensive sow herds, appearing mainly where sows are either restrained in stalls or are tethered, restricting their freedom of choice. First of all, these sows must be protected from using energy intake to maintain body temperature and thus must be housed in adequately insulated buildings during the winter (Nielsen and Danielsen, 1983). MacLean (1969) showed that weight loss or failure to regain adequate body weight after weaning could precipitate infertility. Secondly, there are indications that pigs vary in their ability to cope with a stressful situation, such as tethering. Tethering is stressful because of the necessity for sows to adapt to this situation by developing new behavioural patterns or stereotypies (Cronin, 1985). Through stereotypy behaviour a sow may become highly active, leading to an increased metabolic rate and therefore poorer food conversion (Cronin, Tartwijk, Hel and Verstegen, 1986).

Cariolet and Dantzer (1984) suggested that the 'over-activity' of tethered sows may be associated with the 'thin-sow syndrome'. Gestating sows are given food at about 0.20 above maintenance. If their metabolic rate and thus heat production is increased due to increased activity, less energy will be available for production needs, reducing maternal gain and development. Thus, it is necessary that housing systems be evaluated with 
respect to the energy requirement of sows for maintenance (Close and Cole, 1984).

Therefore, it is clear that the cause of many reproductive disturbances may result from a complex of suboptimal housing conditions, food intake and management factors and in many cases may not be the result of infectious agents or pathological problems.

\section{Neonatal health problems}

Piglets are born physiologically immature but undergo a very distinct and rapid maturation during the first days after birth. A little provocatively, it can be said that a pig that is several days old more closely resembles an adult pig than one which is newborn (Svendsen, Svendsen and Bengtsson, 1986b).

Chilling. The pig is born nearly hairless, and has very little body fat available to catabolize for energy-yielding purposes and for handling low temperatures. In spite of having good carbohydrate reserves, the mobilization system is also immature, so there is a strong need for an external supply of nutrients. Pigs are born sterile, from a sterile environment, and are unable to mount an adequate immune response, relying on the passive immunity provided by sow colostrum (Svendsen et al., 1986b).

The temperature regulatory system of the pig, although immature at birth, matures rapidly. However, within a litter there is a considerable variation between individuals. Body temperature rapidly decreases by 1 to $3^{\circ} \mathrm{C}$ after birth, reaching normal levels ( $\mathrm{ca} .39^{\circ} \mathrm{C}$ ) again within 8 to $18 \mathrm{~h}$. However, the body temperature of small pigs decreases to a greater extent and rises more slowly than does that of large pigs. Weak-born pigs also develop a lower body temperature than 'normal' littermates and usually take a much longer time to attain 'normal' levels (Ahlmann, Svendsen and Bengtsson, 1983).

If a heated creep area near the sow is not provided, cold exposure will cause the litter to huddle, seeking warmth. This thermoregulatory behaviour probably leads to a reduction in nursing vigour, reducing suckling and the amount of colostrum consumed (LeDividich and Noblet, 1981). In consequence the serum and intestinal concentrations of colostral immunoglobulins will be lowered and thus passive antibody protection will be reduced in cold-exposed, newborn neonatal pigs. This is very important where the dam is vaccinated to protect the neonate against certain diseases via colostral antibodies. Cold stress may also affect both antibody and cell-mediate immunity (Kelley, 1983). Therefore, the problem of cold exposure and newborn pigs is very complex, with many factors to be considered.

Crushing. After birth, the newborn pig usually rises quickly and begins to look for the udder, with normal pigs finding it within $20 \mathrm{~min}$ or less. This is an excellent method of evaluating the viability of the newborn pig, since the longer the time the pig takes to reach the udder, the greater the chances of it dying within the first days after birth (Svendsen, et al., 1986b). From these first steps, young pigs are in danger of being crushed or traumatized by the sow.

Nearly all the deaths from crushing occur during the first 24 to $36 \mathrm{~h}$, accounting for a significant proportion of the neonatal mortality of normal size pigs which do not have locomotor or other problems. However, during this period there are many incidences of crushing that do not immediately result in death but which may lead to unobserved injury and/or the pig being more susceptible to infection, with death occurring at a later date. Therefore, the actual losses due to trauma may be ultimately even higher. These losses can be reduced by simple management procedures such as removing the litter from the sow before and during feeding times for the first two or three sow feedings (Svendsen et al., 1986a). Standardizing the litters according to birth weight also helps in reducing these losses but requires group or batch farrowings.

Svendsen and Bengtsson (1985) showed that the smallest numbers of crushed pigs, the lowest numbers of infections, the fewest deaths and the best growth rates up to weaning were obtained in a special production system with group farrowings. In this system, the sows farrowed in a separate farrowing house or unit in which there was very controlled environmental conditions. The farrowing box had moveable heat lamps with one lamp on either side of the sow and fenders on the farrowing crate to guide the sow when she lay down. After a week, the sow and her litter were moved to a conventional lactation unit.

Therefore, many neonatal losses are affected by the housing and management conditions in the herd. Reduction of stress during the gestation period may also help to reduce these losses. Sows housed loose in small groups (six to eight sows) during the gestation period have fewer pigs dying due to asphyxia than do sows fixed in stalls and the piglets have fewer infections (Svendsen and Bengtsson, 1985).

\section{Injuries}

General. Injury is not so much a determinant, as an index of welfare (Webb and Nilsson, 1983). Injuries not only contribute significantly to mortality rates, as seen in neonatal crushings, but may also affect the performance of pigs and provide a source of entry for an infection or secondary problem which in turn may lead to death.

Hoof problems, lameness, leg weakness. Most intensive livestock systems implicitly deny the necessity of regular exercise to maintain health. Some regular exercise is beneficial to the animal, helping to prevent injury by developing greater strength and sensory-motor coordination (Webb and Nilsson, 1983). While genetics and feeding systems, may play a large rôle in these problems, other factors are important. Surveys show that the overall incidence of lameness has not been reduced over a period of several years (Penny, 1982), in 
spite of manufacturers' claims that the commercially available floors are designed to minimize or eliminate injury. The lack of a common standard for describing the characteristics of floors and their effects has made it impossible to compare test results and to achieve some progress in this area (Webb and Nilsson, 1983). Injuries incurred must be evaluated with respect to the incidence, location, depth and size of the injuries and with respect to the animals' age (Svendsen, Olsson and Nilsson, 1979).

Reduced productivity and high incidences of hoof injuries, joint inflamation and lameness have been reported from herds housed in farrowing pens which have had worn and damaged floors (Smith and Mitchell, 1976), or have had concrete floors which have been highly alkaline (high pH) (Penny, Edwards and Mulley, 1971). The design of the farrowing pen, the floor construction, the treatment of the floor surface and the type and the amount of bedding material play a primary etiological rôle in the appearance and development of leg injuries in sucking pigs (Penny, Osborne, Wright and Stephens, 1971; Smith and Mitchell, 1976). Floor hardness is a factor that considerably affects health and well being. Hard floors without straw lead to pressure injuries and also have a lower slip resistance (friction) (Webb and Nilsson, 1983). Slippery floors may be a problem especially if the pigs are genetically predisposed to leg weakness. However, after comparing three different types of perforated floors for piglets, Bengtsson, Fajersson and Svendsen (1982) in noting that none of the floors was 'perfect', postulated that there would probably always be a certain low level of injuries irrespective of the floor type used.

Tail biting. Tail biting may be a symptom of environmental problems. Many factors such as grouping, animal density and lack of bedding have been implicated in the etiology. Slatted floors and liquid manure systems also appear to be predisposing factors (Lindqvist, 1974; Madsen, Nielson and Sogaard, 1978). Food type and feeding routines may also be involved: lack of trough space, restricted feeding and lack of water are often mentioned as causes of tail biting (Smith and Penny, 1981)

Martinsson (1984) noted that generally gilts are those that bite and castrated males are those that are bitten. Others have reported that it is at least one pig, frequently a small-sized gilt that starts biting. Hansen and Hagelso (1979) showed an increasing frequency of tail biting with decreasing trough space in pigs given food ad libitum and kept on slatted floors. The lower ranking pigs were noticeably more aggressive, especially during feeding, and often attacked from behind in attempts to drive higher ranking pigs from the trough. In our research herd, gilts were often the culprits; however, tail biting was observed in pens with solid floors, in pens with straw bedding and in pens in which there was adequate trough space. Also it occurred in pens with ad libitum feeding and in those with restricted feeding.
Teeth clipping, tail docking and castrations. Acute generalized bacterial infections are responsible for about $10 \%$ of the primary pre-weaning mortality (Nielsen, Christensen, Bille and Larsen, 1974), with septicaemias making up a major portion of these losses (Anonymous, 1959). Although the sow, and not the environment, is the primary source of streptococcal infections in sucking pigs, management procedures such as clipping of the canine teeth and tail docking increase the incidence of such infections (Riising, Nielsen, Bille and Svendsen, 1976). The castration of male pigs is a common management procedure in most countries. However, pigs castrated at about 7 days of age have been shown to have fewer abscesses at slaughter than those castrated at 4 to 6 weeks (Martinsson, 1984).

Summary. Injuries act as sites of entry for infectious agents. The presence of hoof and tail lesions in pigs at slaughter has been strongly correlated to the incidences of anaemia, of severe pneumonia, of polyarthritis and of arthritis (Flesja and Ulvesaeter, 1980). Similar lesions are correlated with the incidence of pyaemia and anaemia, possibly due to a depressive effect of the pyogenic processes on hematopoiesis (Jubb and Kennedy, 1970). Also abscesses are very often seen together with tail lesions (Flesja and Ulvesaeter 1980). Post-mortem examinations of sows (Flesja and Ulvesaeter 1979) show that pyaemia and abcesses(es) occur at higher rates in sows than in pigs slaughtered at lighter live weights for meat. Sows have a low frequency of tail lesions: however, hoof lesions, decubitus and neck wounds (from neck tethers) are more common and also serve as portal of entry for pyogenic processes.

\section{Respiratory diseases}

Respiratory problems in pigs are principally associated with infections caused by Mycoplasma hyopneumonia, Pasteurella multocida, Bordatella bronchiseptica and Haemophilus parahaemolyticus but other organisms have been implicated, depending on circumstances. In some cases, two or more organisms may be involved in the pathogenesis. However, disease studies in domestic animals have focussed mainly on the microbial causes, and the rôle of environmental factors in pathogenesis has largely been neglected (Jericho, 1968).

Air pollutants are of especial importance in that they may increase an animal's susceptibility to infective agents. Since the respiratory tract is in intimate and continuous contact with the environment, the relationship between it and air pollutants is critical (Drummond, Curtis, Meyer, Simon and Norton, 1981). Ehrlich (1963) suggested that in places where concentrations of air pollutants were low, damage to the respiratory tract might not be apparent, unless the subject were challenged by an infective microbe.

Air pollutants are usually present in two forms: as gases or as aerosols. Gases of particular importance in 
pig housing are ammonia and hydrogen sulphide (Gustafsson and Martensson, 1986). The concentration of these gases in pig housing increases with stocking rate and is affected by the type of manure disposal and ventilation systems. Ammonia is a concern in housing with solid manure systems, accepted levels being 15 to 25 ppm, whereas hydrogen sulphide gas is a concern where there are liquid manure systems. Hydrogen sulphide should not be present in detectable concentrations in animal houses.

The respiratory tract lining is normally covered with aqueous mucus. Thus gases, such as ammonia which are highly soluble in water, will be absorbed from the inspired air by the upper respiratory mucus and rarely reach the lungs (Curtis, Anderson, Simon, Jensen, Day and Kelley, 1975). However, aerial dust may absorb and carry gases (Day, Hansen and Andersen, 1965; Burnett, 1969) and ammonia may reach the lungs via transport by dust particles in aerosols (LaBelle, Long and Christofano, 1955).

Exposure to dust has been associated with pneumoconioses, allergies and toxic effects (Honey and McQuitty, 1976). The evidence that chronic exposure to dust increases susceptibility to respiratory infections is conflicting. Holt and Keast (1977) concluded that dust may stimulate or depress the human immune system depending on dose and duration of exposure. The fate of an inhaled dust particle and the subsequent hazard to the animal depends on many factors; more particularly on its physical, chemical and biological properties (Whittlestone, 1976). Particles greater than $5 \mu \mathrm{m}$ in diameter are deposited in the upper respiratory tract, while smaller particles penetrate to the bronchioles and alveoli (Bruce, 1964). Even minor structural damage to the epithelium of the upper respiratory tract may lead to severe functional impairment and an increased incidence and severity of lung disease (Doig and Willoughby, 1971; Curtis, Jensen, Simon and Day, 1974).

Airborne dust aerosols in animal houses arise from two main sources; the animals, as skin squames, and the bedding. Food and feeding systems have been implicated but Nilsson (1982) showed that the type of food or the feeding system had no significant effect on dust concentration in pig houses, although there was more dust with ad libitum feeding than with restricted feeding. Under most conditions, very little dust is introduced by the ventilation system (Nilsson, 1982). Dust levels exhibit marked diurnal cycles and are generally highest during stall rebedding and feeding (Crichlow, Yoshida and Wallace, 1980). The most important factor with respect to dust levels is the activity of the animals but stocking density also appears to affect the amount of dust present (Nilsson, 1982).

Microbial aerosols may contain bacteria, viruses and fungal spores. The origin is similar to that of dust. Once airborne, the survival of micro-organisms depends on temperature, humidity and, under natural conditions, non-ionizing radiation (Strange and Cox, 1976). These effects are complex and vary considerably between species of viruses and bacteria (Donaldson, 1978). The levels of airborne bacteria, endotoxins and fungi in the dust of pig houses are in the range that cause clinical effects in humans. Approximately $26 \%$ of the airborne viable gram-negative bacteria are in the respirable range (Clark, Rylander and Larsson, 1983).

Transmission of respiratory infection usually takes place via aerosols over short distances, which suggests that relatively large particles which sediment rapidly may be mainly responsible for transferring the causal organism from one pig to the next. However, some unexplained infections do occur at greater distances, and this suggests that smaller particles which remain suspended for longer periods may sometimes be responsible (Whittlestone, 1976).

Housed animals must endure a possibly contaminated atmosphere and may also be exposed to several potentially harmful contaminants simultaneously. Pigs kept in an ammonia contaminated atmosphere harbour more bacteria in their lungs than do controls. Atmosphere contaminated with 50 or $75 \mathrm{ppm}$ ammonia inhibits the clearance of inhaled bacteria from the lungs, as do cold temperatures $\left(6^{\circ} \mathrm{C}\right)$ in pigs younger than 2 weeks old. Week-old pigs harbour more viable bacteria in their lungs than do 2-week old pigs (Drummond, Curtis and Simon, 1978).

Other factors also play a rôle in the development of respiratory disease, especially under conditions of poor management and hygiene. The frequent introduction of new animals into the herd and frequent climatic changes in houses will also increase the incidence (Nielsen, Bille, Svendsen and Riising, 1976). When weaners are bought from several farms, there is always a risk that they have subclinical disease or are carriers of contagion. However, it is rare that growing-pig houses with a good environment and which are well managed have a high proportion of disease notations at slaughter (Martinsson and Lundeheim, 1985). Dense populations of pigs housed in poorly ventilated buildings frequently show a high prevalence of extensive lesions of enzootic pneumonia (Whittlestone, 1976).

When animals are heat or cold stressed they exhibit characteristic changes in behaviour. Cold-stressed animals seek shelter and huddle, thereby increasing animal density. Reduced ventilation rates lead to increased air moisture. The combined effects of increased population density and elevated air moisture could increase microbial insults (Kelley, 1983). This increased microbial challenge may result in the association between cool weather and respiratory disease (Webster, 1981). In addition, body chilling may reduce the effectiveness of the ciliary clearance mechanisms in the pig, permitting bacteria already present in the lung to assume a pathogenic rôle (Whittlestone, 1976). As mentioned previously, cold stress in general may affect the immune system. 
It is the aim of the various types of minimal disease programmes to provide animals which are free of specific infections. Thus, in specific-pathogen-free herds very low levels of respiratory diseases are reported although environmental conditions such as the level of gases or dust, may be poor. Environmental factors may increase the susceptibility of the animal, promote the spread of contagion, or affect the severity of the disease, but in general they do not cause a specific disease. The evidence relating the occurrence of specific disease and environmental factors is in many cases circumstantial; however, alleviating poor environment often leads to a reduction in illness. Nilsson and Gustafsson (1986) showed that relatively simple methods, such as building growing-pig pens with solid walls, with front ventilation and with dust-reducing measures such as the provision of showers for the pigs, especially just before weighing time, lead to a gradual improvement in health.

\section{Intestinal problems}

General. Intestinal problems may be said to be one of the 'plagues' of pig production. Extending over the entire production period, from the first neonatal diarrhoeas to the final, inexplicable growing-pig death, the multifactorial nature of these problems is acknowledged, but not always understood. Some gastrointestinal disturbances in which environmental factors may play an important rôle will be briefly described and where possible, discussed.

Post-weaning diarrhoea. A major factor in the occurrence of Escherichia coli-associated post-weaning diarrhoea may be the sudden and abrupt removal of the sows' milk. This milk not only contains antibodies against environmental pathogens but also contains active hormones and growth factors, the importance of which are not understood at present (Svendsen, Weström, Svendsen, Ohlsson, Ekman and Karlson, 1986) Weström, Ekman, Svendsen, Svendsen and Karlsson, 1986). However, managemental and environmental factors may also be important in the pathogenesis of this disease. Weaning is a stressful period: the pigs are abruptly separated from the sow; often they are moved to a new environment; 500 to $600 \mathrm{ml}$ daily of sow milk for each pig is replaced by solid food; water has suddenly to be drunk in greater quantities and this may not be continually available and/or may come from drinking nipples to which pigs are not accustomed, or it has to be taken from drinking troughs with poor water hygiene. In addition, separation from the sow may change the hygiene and behavioural patterns of the pigs and the environmental temperature may decrease. These factors may predispose to post weaning E.coli diarrhoea (Svendsen, 1979).

Runt syndrome. Runts are pigs which fail to thrive after the initial shock of weaning. They are generally considered to be the result of a chronic intestinal infection or other chronic illness affecting absorption processes (Rowland and Lawson, 1982). However, Jönsson and Martinsson (1976) showed that many of these pigs appear to be chronically stressed; they have atrophied thymus and intestinal villi, enlarged adrenal glands, and increased levels of stress hormones. Cronin (1985) noted that certain pigs are apparently less able to withstand stress but no connection with pale, soft, exudative muscle at slaughter has been observed. Secondary infections are often seen (Martinsson, 1984), and in some cases they may account for the observations reported for intestinal disturbances in growing pigs.

Intestinal haemorhage syndrome. A peracute, fatal enterrhagic syndrome named intestinal haemorahage syndrome was first reported in Britain (Jones, 1967). Although also seen in sows (Smith, 1984) it is an increasing problem in 45 to $85 \mathrm{~kg}$ growing pigs in Denmark (Nielsen, 1986). The mortality is often 2 to $6 \%$ in affected herds. The syndrome is characterized by sudden colic and by death occurring within a few minutes due to rapid blood loss into the intestines. Farmers call the pigs 'balloon pigs' because of the rapid swelling of the abdomen. The true incidence is difficult to determine because the syndrome may be diagnosed as abdominal torsion. At first, it was ascribed to a hygiene problem because disinfection had some effect in reducing the incidence. However, subsequent observations have indicated that stocking density may be a major factor. Other components of the environment and of management procedures may also be important.

Abdominal torsion. The incidence of fatalities due to abdominal torsion appears to be increasing in both sows and in growing pigs, usually in animals from large modern units. Reasons for this apparent increase in the number of torsions of the abdominal organs in sows in recent years are not clear. In some herds, the problem has been related apparently to a change in the order, the mode, or the time of feeding, leading to the animals being stressed. Rough movements and manipulations of sows have been incriminated in some cases. Any situation causing increased agitation or nervousness in the animals may favour the development of the condition. It is not unusual to find torsions of different organs in the same outbreak (Smith, 1984; Morin, 1986).

\section{CONCLUDING REMARKS}

It is the total effect of the different environmental factors, including the presence of various types of contaminants, which determine herd health. Since there are many possible combinations and the clinical manifestation of disease often remains the same, it is often very difficult to determine causal relationships. In the case of infectious disease a primary requirement is the presence of the infective agent in the population. Unfavourable environmental factors do not result in a specific disease if the agent is missing. 
The key to better management and to controlling problems in pig production is to establish an animal identification and record keeping system. Computers and electronic systems should prove to be a great help in this task and several management production systems are available to producers. However, many of these systems are not set up to provide adequate information about individual animals in particular and about herd health in general, a failure which must be remedied in future.

Identifying and solving the very complex herd health problems in modern pig production requires a coordinated multidiscplinary approach between biologists and technicians. There is a need for further studies on how environmental factors interact and how they affect the animals.

\section{REFERENCES}

Ahlmann, K., Svendenen, J. and Bengtsson, A.-Ch. 1983 [Rectal temperature of the newborn pig measured under different environmental conditions.] Report, Swedish University of Agricultural Sciences, Department of Farm Buildings, Lund, No. 31 .

Almond, G. W., Bosu, W. T. K., King, G. J. and WILSON, M. R. 1983. The 'not in pig' sow. Proceedings of 5th International Conference on Production Diseases in Farm Animals, Uppsala, pp. 260. Swedish University of Agricultural Sciences.

Anonymous. 1959. A survey of the incidence and causes of mortality in pigs. I. Sow survey. Veterinary Record 71: 777-786.

Bengtsson, A.-C., Fajersson, P. and Svendsen, J. 1982. [Leg injuries of piglets - a comparative study using three different floor types.] Report Swedish University of Agricultural Sciences, Department of Farm Buildings, Lund, No. 26.

BEVIER, G. W. and BÄcKSTröM, L. 1980. Seasonal infertility pattern during 1978 in 22 swine herds in Iowa and Nebraska, USA. Proceedings of 6th International Pig Veterinary Society Congress, Copenhagen, p. 321 (Abstr.).

BEVIER, G. W. and DiAL, G. D. 1983. Reproductive disorders with special emphasis to management in swine. Proceedings of 5 th International Conference on Production Diseases in Farm Animals, Uppsala, pp. 55-56. Swedish University of Agricultural Sciences.

Bruce, J. M. 1964. Comparative study of the aerobiology of two types of pig house. M.Sc. Thesis, University of Newcastle-upon-Tyne.

BurnetT, W. E. 1969. Odor transport by particulate matter in high density poultry houses. Poultry Science 48: 182-185.
CARIolet, R. and Dantzer, R. 1984. Motor activity of tethered sows during pregnancy. Annales de Recherches Véterinaries 15: 257-261.

Clark, S., Rylander, R. and larsson, L. 1983. Airborne bacteria, endotoxin and fungi in dust in poultry and swine confinement buildings. American Industrial Hygiene Association Journal 44: $537-541$.

Close, W. H. and Cole, D. J. A. 1984. Principles and strategies involved in the nutrition of the sow. 35th Annual Meeting of the European Association of Animal Production, The Hague, Paper NP2, pp. $1-11$.

Corteel, J. M., Signoret, J. P. and du Mesnil du Buisson, F. 1964. Variations saisonnieres de la reproduction de la truie et facteurs favorisant l'anestrus temporaire. Proceedings of 5 th International Congress on Animal Reproduction and Artificial Insemination, pp. 536-540.

Crichlow, E. C., Yoshida, K. and Wallace, K. 1980. Dust levels in a riding stable. Equine Veterinary Journal 12: 185-188.

Cronin, G. M. 1985. The development and significance of abnormal stereotyped behaviours in tethered sows. Ph.D. Thesis, University of Wageningen.

Cronin, G. M., Tartwijk, J. M. F. M. van, Hel, W. VAN Der and Verstegen, M. W. A. 1986. The influence of degree of adaptation to tether-housing by sows in relation to behaviour and energy metabolism. Animal Production 42: 257-268.

Curtis, S. E., Anderson, C. R., Simon, J., Jensen, A. H., DAY, D. L. and Kelley, K. W. 1975. Effects of aerial ammonia, hydrogen sulphide and swinehouse dust on rate of gain and respiratory-tract structure in swine. Journal of Animal Science 41: 735-739.

Curtis, S. E., Jensen, A. H., Simon, J. and Day, D. L. 1974. Effects of aerial ammonia, hydrogen sulphide and swine house dust, alone and combined, on swine health and performance. Proceedings of 1st International Livestock Environment Symposium, Lincoln, Nebraska, pp. 209-210.

Day, D. L., Hansen, E. L. and Anderson, S. 1965. Gases and odors in confinement swine buildings. Transactions of the American Society of Agricultural Engineers 8: 118-121.

Doig, P. A. and WilloughBy, R. A. 1971. Response of swine to atmospheric ammonia and organic dust. Journal of the American Veterinary Medical Association 159: 1353-1361.

Donaldson, A. I. 1978. Factors influencing the dispersal, survival and deposition of airborne pathogens of farm animals. Veterinary Bulletin 48: 83-94.

Drummond, J. G., Curtis, S. E., Meyer, R. C., Simon, J. and Norton, H. W. 1981. Effects of atmospheric ammonia on young pigs experimentally infected with Bordetella bronchiseptica. 
American Journal of Veterinary Medical Research 42: 963-968.

Drummond, J. G., Curtis, S. E., and Simon, J. 1978. Effects of atmospheric ammonia on pulmonary bacterial clearance in the young pig. American Journal of Veterinary Medical Research 39: 211212.

Dyck, G. W. 1973. Effects of a cold environment and growth rate on reproductive efficiency in gilts. Canadian Journal of Animal Science 54: 287-292.

Edwards, R. L., Omtvedt, I. T., Turman, E. J., Stephens, D. F. and Mahoney, G. W. A. 1968. Reproductive performance of gilts following heat stress prior to breeding and in early gestation. Journal of Animal Science 27: 1634-1637.

EHRLICH, R. 1963. Effect of air pollutants on respiratory infection. Archives of Environmental Health 6: 638-642.

FAbIANSSON, S. 1986. The SIG-PIG syndrome and its cause - social pressures at regrouping. Proceed ings of 9th International Pig Veterinary Society Congress, Barcelona, p. 473 (Abstr.).

Flesja, K. I. and Ulvesaeter, H. O. 1979. Pathological lesions in swine at slaughter. II. Culled sows. Acta Veterinaria Scandinavica 20: 515-524.

Flesja, K. I. and Ulvesaeter, H. O. 1980. Pathological lesions in swine at slaughter. III. Inter-relationship between pathological lesions, and between pathological lesions and 1) carcass quality and 2) carcass weight. Acta Veterinaria Scandinavica 21: Suppl. 74, pp. 1-22.

Freeman, B. M. 1975. Physiological basis of stress. Proceedings of the Royal Society of Medicine 68: 427-429.

Gustafson, G. and Martensson, L. 1986. [Basic information on ammonia and hydrogen sulphide levels for ventilation.] Nordisk Jordbruksforskning-section VII, Seminar 3-5. $14 \mathrm{pp}$.

Hansen, L. L. and Hagelos, A. M. 1979. Environmental influence on the social hierarch function in pigs. Proceedings of the European Association of Animal Production, Harrogate.

Heitman, H., Hughes, E. H. and Kelly, C. J. 1951. Effects of elevated ambient temperatures on pregnant sows. Journal of Animal Science 10: 907-915.

Holt, P. G. and Kenst, D. 1977. Environmental induced changes in immunological function: acute and chronic effects of inhalation of tobacco smoke and other atmostpheric contaminants in man and experimental animals. Bacteriological Reviews 41: 205-216.

Honey, L. F. and McQuitty, J. B. 1976. Dust in the animal environment. Research Bulletin, University of Alberta, No. 76-2.

Hurtgen, J. P. 1981. Influence of housing and management factors on reproductive efficiency of swine. Journal of the American Veterinary Medical Association 179: 74-78.

Hurtgen, J. P. and Leman, A. D. 1980. Seasonal influence on the fertility of sows and gilts. Journal of the American Veterinary Medical Association 177: 631-635.

JERICHO, K. W. F. 1968. Pathogenesis of pneumonia in pigs. Veterinary Record 82: 507-520.

JoNES, J. E. T. 1967. An intestinal haemorrhage syndrome in pigs. British Veterinary Journal 123: 286-293.

Jönsson, L. and Martinsson, K. 1976. Regional ileitis in pigs. Morphological and pathogenetical aspects. Acta Veterinaria Scandinavica 17: 223-232.

Jubb, K. V. and Kennedy, P. C. 1970. Pathology of Domestic Animals. Vol. 1. 2nd ed. Academic Press, New York.

Kelley, K. W. 1983. Immunobiology of domestic animal as affected by hot and cold weather. Transactions of the American Society of Agricultural Engineers 26: 834-840.

LaBelle, C. W. Long, J. E. and Christofano, E. E. 1955. Synergistic effects of aerosols: particulates as carriers of toxic vapours. Archives of Industrial Health 11: 297-304.

LeDividich, J. and Noblet, J. 1981. Colostrum intake and thermoregulation in the neonatal pig in relation to environmental temperature. Biology of the Neonate 40: 167-174.

Leman, A. D., Greenley, W. and Barrick, G. 1986. Retrospective study of the influence of housing on farrowing rates. Proceedings 9th International Pig Veterinary Society Congress, Barcelona, p. 18 (Abstr.).

LindQvist, J.-O. 1974. Animal health and environment in the production of fattening pigs. A study of disease incidence in relation to certain environmental factors, daily weight gain and carcass classification. Acta Veterinaria Scandinavica Suppl. 51.

Love, R. J. 1978. Definition of a seasonal infertility problem in pigs. Veterinary Record 103: 443-446.

MaCLEan, C. W. 1969. Observations on non-infectious infertility in sows. Veterinary Record 85: 675-681.

Madsen, A., Nielsen, E. K. and SogaArd, Aa. 1978. [Environmental influence on health of bacon pigs.] Beretning fra Statens Husdyrbrugsfors $\phi g$ 472, pp. 1.44.

Martinsson, K. 1984. [Health care in slaughter swine.] In Problemkomplex och Atgärdsprogram vid Nagra Vanliga Hälsostörningar. Pig Production Medical Unit, Kristianstad.

Martinsson, K. and Lundeheim, N. 1985. [Prevalence of different diseases at slaughter in pigs brought into the herd as weaners.] Svensk Veterinartidning 37: 815-820.

MORIN, M. 1986. Torsion of abdominal organs in sows. Proceedings of 9th International Pig Veterinary 
Society Congress, Barcelona, p. 382 (Abstr.).

Nielsen, H. E. and Danielsen, V. 1983. The problem of thin sows. 5th International Conference on Production Diseases in Farm Animals, Uppsala, p. 61. Swedish University of Agricultural Sciences.

NiELSEN, N. C. 1986. [Intestinal bleeding in pigs - a present-day problem.] Proceedings of XVth Nordic Veterinary Congress, Stockholm, pp. 387-390. Swedish Veterinary Association.

Nielsen, N. C., Bille, N., Svendsen, J. and Riising, H.-J. 1976. Sygdomsbekaempelse $i$ Svinebesaetninger. Department of Internal Medicine, Royal College of Veterinary Medicine and Agriculture, Copenhagen.

Nielsen, N. C., Christensen, K., Bille, N. and LarSen, J. L. 1974. Preweaning mortality in pigs. 1. Herd investigations. Nordisk Veterinaermedicin 26: $137-150$.

Nilsson, C. 1982. [Dust investigations in pig houses.] Report, Swedish University of Agricultural Sciences, Department of Farm Buildings, Division of Building Construction, Lund, No. 25.

Nilsson, C. and Gustafsson, G. 1986. [Dust in slaughter swine houses.] Special Report, Swedish University of Agricultural Sciences, Department of Farm Buildings, Division of Building Construction, Lund. In press.

Omtvedt, I. T., Nelson, R. E., Edwards, R. L., Stephens, D. F. and Turman, E. J. 1986. Influence of heat stress during early, mid and late pregnancy of gilts. Journal of Animal Science 32: 312-317.

Paterson, A. M., Barker, I. and Lindsay, D. R. 1978. Summer infertility in pigs: Its incidence and characteristics in an Australian commercial piggery. Australian Journal of Experimental Agriculture and Animal Husbandry 18: 698-701.

Penny, R. H. C. 1982. Pig housing: The influence of the 'Built Environment'. What are the losses and what is the cost? Farm Buildings Association Journal 30: 33-41.

Penny, R. H. C., Edwards, M. J. and Mulley, R. 1971. Clinical observations of necrosis of the skin of suckling piglets. Australian Veterinary Journal 47: 529537 .

Penny, R. H. C., Osborne, A. D., Wright, A. I. and STEPHENS, T. K. 1971. Footrot in pigs: Observations on the clinical disease. Veterinary Record 77: 101-108.

Rising, H.-J., Nielsen, N. C., Bille, B. and SVENDSEN, J. 1976. Streptococcal infections in suckling pigs. I. Epidemiological investigations. Nordisk Veterinaermedicin 28: 65-79.

Rowland, A. C. and Lawson, G. H. K. 1981. Intestinal adenomatosis complex (porcine proliferative enteropathies). In Diseases of Swine, 5th ed. (ed. A. D. Leman, R. D. Glock, W. L. Mengeling, R. H. C. Penny, E. Scholl and B.
Straw), pp. 517-529. Iowa State University Press, Ames, Ia.

SELYE, H. 1956. Stress. Stockholm.

Selye, H. 1974. Stress without Distress. Hodder and Stoughton, London.

SмrтH, W. 1984. Sow mortality - limited survey. Proceedings of 8th International Pig Veterinary Society Congress, Ghent, p. 368 (Abstr.).

SMith, W. J. and Mitchell, C. D. 1976. Floor surface treatment to prevent lameness in suckling piglets. Farm Building Progress, January, pp. 17-19.

Smith, W. J. and Penny, R. H. C. 1981. Behavioural problems, including vices and cannibalism. In Diseases of Swine, 5 th ed. (ed. A. D. Leman, R. D. Glock, W. L. Mengeling, R. H. C. Penny, E. Scholl and B. Straw), pp. 671-680. Iowa State University Press, Ames, Ia.

STORK, M. G. 1979. Seasonal reproductive inefficiency in large pig breeding units in Britain. Veterinary Record 104: 49-52.

Strange, R. E. and Cox, C. S. 1976. Survival of dried airborne bacteria. In The Survival of Vegetative Microbes (ed. T. A. G. Gray and J. A. Postgate), 26th Symposium of the Society of General Microbiology, Cambridge, pp. 111-154.

SVENDSEN, J. 1979. Enteric Escherichia coli infections in suckling pigs and in pigs at weaning. Aspects of pathogenesis, prevention and control. Ph.D. Thesis, Swedish University of Agricultural Sciences.

Svendsen, J. and Bengtsson, A.-Ch. 1985. [Housing systems for piglet production.] Research Leaders Meeting, Konsulentavd, rapporter, Allamänt 65, pp. 1:1-1:9. Swedish University of Agricultural Sciences, Uppsala.

Svendsen, J., Bengtsson, A.-Ch. and Svenden, L. S. $1986 \mathrm{a}$. Occurrence and causes of traumatic injuries in neonatal pigs. Pig News and Information 7: $159-170$.

Svendsen, J., Olsson, O. and Nilsson, C. 1979. The occurrence of leg injuries on piglets with the various treatment of the floor surface of the farrowing pen. Nordisk Veterinaermedicin 31: 49-61.

Svendsen, J., Svendosen, L. S. and Bengtsson, A.-Ch. 1986b. Reducing perinatal mortality. In Diseases of Swine 6th ed., pp. 813-824. Iowa State University Press, Ames.

Svendsen, L. S., Weström, B. R., Svendsen, J.. Ohlsson, B. G., EkMAN, R. and Karlsson, B. W. 1986c. Insulin involvement in intestinal macromolecular transmission and closure in neonatal pig. Journal of Pediatric Gastroenterology and Nutrition 5: 299-304.

Teague, H. S. 1970. Effect of temperature and humidity on reproduction. Proceedings of Symposium on Effect of Disease and Stress on Reproductive Efficiency in Swine, University of Nebraska, pp. 21-26. 
Tompkins, E. C., Heidenreich, C. J. and Stob, M. 1967. Effect of post-breeding thermal stress on embryonic mortality in swine. Journal of Animal Science 26: 377-380.

Trujano, M. and Wrathall, A. E. 1986. Effects of hyperthermia on cultured porcine embryos. Proceedings of 9th International Pig Veterinary Society Congress, Barcelona, p. 42 (Abstr.).

Vannier, P., Tillon, J. P., Madec, F. and Morisse, J. P. 1983. Environment and gastro-enteritis. Annales de Recherches Véterinaires 14: 450-455.

Venturi, A. and Patrizia, T. 1986. Effects of high ambient temperatures on the rectal temperatures of sows. Proceedings of 9th International Pig Veterinary Society Congress, Barcelona, p. 53 (Abstr.).

Warnick, A. C. L., Wallace, H. D., Palmer, A. Z., SosA, E., Duerre, D. J. and Caldwell, V. E. 1965. Effect of temperature on early embryo survival in gilts. Journal of Animal Science 24: 89-92.

WebB, N. G. and Nilsson, C. 1983. Flooring and injury - an overview. In Farm Animal Housing and
Welfare (ed. S. H. Baxter, M. R. Baxter and J. A. C. MacCormack), pp. 226-261. Martinus Nijhoff, The Hague.

Webster, A. J. F. 1970. Environmental and physiological interactions influencing resistance to infectious disease. In Resistance to Infectious Disease (ed. R. H. Dunlop and H. W. Moon), pp. 60-80. Modern Press, Saskatoon.

Webster, A. J. F. 1981. Weather and infectious disease in cattle. Veterinary Record 108: 183-187.

Weström, B. R., Ekman, R., Svendsen, L. S., Svendsen, J. and Karlsson, B. W. 1986. Levels of immunoreactive insulin, neurotensin and bombesin in porcine colostrum and milk. Journal of Pediatric Gastroenterology and Nutrition 5: 299-304.

Whithlestone, P. 1976. Effect of climatic conditions on enzootic pneumonia of pigs. International Journal of Biometeorology 20: 42-48.

Wildt, D. E., Riegle, G. D. and Dukelow, W. R. 1975. Physiological temperature response and embryonic mortality in stress swine. American Journal of Physiology 229: 1471-1475. 